\title{
Der Mensch zwischen Weltflucht und Weltverantwortung
}

Lebensmodelle der paganen und der jüdisch-christlichen Antike

Hrsg. v. Heinz-Günther Nesselrath u. Meike Rühl

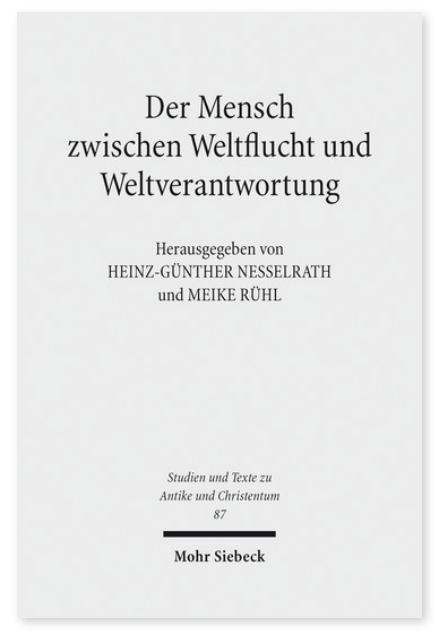

2014. VI, 192 Seiten. STAC 87

ISBN 978-3-16-153092-0 DOI 10.1628/978-3-16-153092-0 eBook PDF 74,00€

ISBN 978-3-16-153091-3 fadengeheftete Broschur 74,00€
Die Beiträge des vorliegenden Bandes leuchten die kulturellen, historischen und religiösen oder philosophischen Muster und Modalitäten aus, die die Menschen der Antike zur Wahl einer bestimmten Lebensform veranlasst haben, und untersuchen die Darstellung und Beurteilung dieser Lebensmodelle in Bild- und Textmedien. Im Mittelpunkt steht dabei jeweils die Frage nach dem Verhältnis zur 'Welt' und die Position im Spannungsfeld von Zugewandtheit und Distanzierung, Diesseits- oder Jenseitsorientierung, Rückzug und Verantwortung, schließlich auch zwischen Modell und Realisierung.

Die Autoren stammen aus den Fächern der klassischen Altertumswissenschaft und Byzantinistik sowie der Theologie, die Beiträge gehen zurück auf das Symposion 'Menschenbilder zwischen Weltverantwortung und Weltflucht' des Graduiertenkollegs »Götterbilder - Gottesbilder - Weltbilder« der Universität Göttingen.

Inhaltsübersicht

A. Pagane Antike Adolf Borbein: Bürger in der Polis: Das Menschenbild der klassischen griechischen Kunst - Heinz-Günther Nesselrath: Ein homerischer Held im Konflikt mit der Welt? Achill zwischen Flucht und Verantwortung in der Ilias und in späterer griechischer Rhetorik - Michael Erler: Weltverantwortung und Weltflucht bei Platon und im Platonismus - Henrik Mouritsen: 'Pagane Lebensmodelle?' Gods, pietas, and maiores in the Roman Republic - Meike Rühl: Flucht nach vorne: Politische und literarische Positionierungen am Ende der römischen Republik - Jula Wildberger: Simus inter exempla! Formen und Funktionen beispielhafter Weltflucht in der frühen Kaiserzeit

B. Jüdisch-christliche Antike Philip Davies: Halakhah and Apocalyptic - Samuel Vollenweider: Weltdistanz und Weltzuwendung im Urchristentum - Andreas Müller: Weltflucht und Weltverantwortung im spätantiken Mönchtum nach der Historia Lausiaka des Palladios von Helenopolis - Claudia Rapp: Die unvollständige Weltflucht des frühen Mönchtums -

Martin Tamcke: Das Menschenbild der christlichen Synoden bei den Ostsyrern zwischen Weltverantwortung und Weltflucht

Heinz-Günther Nesselrath Geboren 1957; 1976-81 Studium der Klassischen Philologie und der Alten Geschichte an der Universität zu Köln; 1981 Promotion; 1987 Habilitation; 1992-2001 vollamtlicher Professor für Klass. Philologie an der Universität Bern; seit 2001 Universitätsprofessor für Klass. Philologie an der Georg-August-Universität Göttingen.

Meike Rühl vertritt die Professur für Klassische Philologie mit dem Schwerpunkt Latein/Mittellatein an der Universität Osnabrück.

Jetzt bestellen:

https://mohrsiebeck.com/buch/der-mensch-zwischen-weltflucht-und-weltverantwortung-9783161530920?no_cache=1 order@mohrsiebeck.com

Telefon: +49 (0)7071-923-17

Telefax: +49 (0)7071-51104 